\title{
EXTRAÇÃO DE LIPASE DE MAMONA (Ricinus communis L.) EM FASE AQUOSA
}

\author{
F. A. Silva ${ }^{1}$, W. Kopp ${ }^{1}$, R. L. C. Giordano ${ }^{1}$ \\ ${ }^{1}$ Universidade Federal de São Carlos, Programa de Pós Graduação em Engenharia Química \\ E-mail para contato: eq.felipe.silva@gmail.com
}

\begin{abstract}
RESUMO - Endospermas de mamona (Ricinus communis L.) processados contendo atividade lipolítica têm sido utilizados com sucesso em alguns bioprocessos. Porém, a toxina ricina presente na mamona limita a aplicação deste biocatalisador, sendo necessário separá-la da lipase. A primeira etapa deste processo é a solubilização do biocatalisador em fase aquosa. Neste contexto, foi avaliada a extração da lipase de mamona em diferentes tampões e pHs. $\mathrm{O}$ extrato bruto de mamona foi incubado em diversos tampões por $12 \mathrm{~h}$ a $25^{\circ} \mathrm{C}$; seguido de centrifugação para separação do endosperma. Os melhores resultados nesta etapa foram obtidos com tampão fosfato 0.05 mol. $\mathrm{L}^{-1} \mathrm{pH} 7.0$, carbonato-bicarbonato 0.05 mol. $\mathrm{L}^{-1} \mathrm{pH} 9.0$ e 10.0 , onde mais de $70 \%$ da atividade lipolítica foi extraída para a fase líquida ao final do processo.
\end{abstract}

\section{INTRODUÇÃO}

Processos enzimáticos, quando comparados com processos catalisados quimicamente, apresentam como principais vantagens a redução do consumo energético do processo, uma vez que enzimas atuam em condições suaves de temperatura e pressão, apresentando alta seletividade e especificidade (Narwal, Gupta 2013). Enzimas são capazes de catalisar reações químicas sem a formação de subprodutos indesejáveis e sem as custosas etapas de proteção e desproteção de grupos reativos necessárias na maioria dos processos onde catalisadores químicos são empregados (Leung et al., 2010).

Atualmente, inúmeras enzimas são empregas em processos industriais, como proteases, celulases e lipases. Dentre estas, lipases (glicerol éster hidrolases, E.C 3.1.1.3) são especialmente interessantes devido sua vasta aplicabilidade - desde a indústria alimentícia, passando pela química fina chegando até a produção de biocombustíveis - fazendo com que sejam alvo de extensa pesquisa científica (Vescovi 2012).

Lipases naturalmente catalisam a hidrólise de óleos e gorduras quando em meio aquoso, de forma parcial ou total. Porém, também são capazes de realizar reações de esterificação, transesterificação (alcoólise) e interesteríficação de lipídeos quando em meio orgânico (Atabani et al., 2012; Adlercreutz 2013). Embora lipases mais utilizadas industrialmente sejam obtidas a partir de fontes microbianas, lipases podem ser obtidas de diferentes fontes, como células animais e vegetais (Pierozan et al., 2009). Enzimas vegetais são novidade em termo de fontes enzimáticas; porém possuem vantagens como baixo custo da matéria-prima, aplicação na indústria farmacêutica e alimentícia, fácil aceitação no mercado devido sua 
natureza vegetal e aplicação direta como biocatalisadores mesmo estando parcialmente purificadas (Seth et al., 2014).

Dentre as lipases de fonte vegetal, a lipase de mamona (Ricinus communis L.) se destaca devido a sua elevada atividade catalítica e baixo custo de obtenção. Além de apresentar pH ótimo ácido (pHs 4.0 a 5.5), algo incomum para lipases. Endospermas de mamona processados contendo atividade lipolítica têm sido utilizados com sucesso em alguns bioprocessos (Tüter 1998, Pierozan et al., 2009, Avelar et al., 2013).

Embora seja possível obter um catalisador eficiente e de baixo custo através do simples processamento de sementes de mamona, a presença da proteína ricina representa um obstáculo para aplicação de lipase de mamona, principalmente, em processos voltados para síntese de químicos finos e compostos farmacêuticos. A ricina é uma proteína de 62-66 kDa, composta por duas cadeias polipeptídicas de aproximadamente $32 \mathrm{kDa}$ e $34 \mathrm{kDa}$ unidas por ligações dissulfeto. A cadeia A é uma potente ribotoxina, que inibe a síntese de proteínas em células; enquanto a cadeia $\mathrm{B}$ é uma lectina, que se liga a resíduos de galactose na membrana celular. A concentração letal da ricina está estimada em $2 \mathrm{mg}$ para um adulto quando há exposição entérica (Godoy et al., 2009, Brandon et al., 2014). Devido ao risco potencial desta toxina, fica clara a necessidade de separa-la da lipase de mamona de forma que esta lipase possa ser aplicada de maneira mais generalizada e sem riscos.

Considerando o potencial da lipase de mamona, a possibilidade de uma maior faixa de aplicação em processos químicos de interesse comercial e a limitação consequente da presença da toxina ricina, este trabalho teve como objetivo estabelecer um processo simples de solubilização da lipase de mamona em fase aquosa. A solubilização da lipase representa a primeira etapa de um processo de purificação que será realizado posteriormente.

\section{MATERIAL E MÉTODOS}

\subsection{Materiais}

Sementes de mamona (Ricinus communis L) foram adquiridas da BR SEEDS LTDA (Araçatuba - SP). Acetato de sódio tri hidratado, etanol anidro, ácido acético glacial, fosfato de sódio monobásico, fosfato de sódio bibásico, carbonato de sódio, bicarbonato de sódio, ácido cítrico, acetona e hidróxido de potássio foram adquiridos da Synth (São Paulo, SP). Tributirina foi adquirido da Sigma-Aldrich (São Paulo, SP). Óleo de soja (Liza) foi adquirido em comércio local. Os demais reagentes utilizados foram de grau analítico.

\subsection{Métodos}

Preparo do extrato bruto de mamona: Sementes de mamona sem casca foram triturados em acetona gelada $\left(4{ }^{\circ} \mathrm{C}\right)$ por 2 minutos; seguido de adição de acetona a fim de completar uma proporção semente/acetona 1:5 (m/v). O material triturado foi mantido sob agitação por 4 horas a $4{ }^{\circ} \mathrm{C}$; filtrado a vácuo e mantido a temperatura ambiente para evaporação da acetona residual. Após seco o material foi peneirado em malha $0,85 \mathrm{~mm}$ e armazenado. Este material foi chamado de extrato bruto de mamona. 
Estabilidade do extrato bruto de mamona em mistura etanol-óleo: Em microtubos plásticos de $2 \mathrm{~mL}$ foram adicionados $0.1 \mathrm{~g}$ de extrato bruto de mamona. Em seguida, em cada tubo foram adicionados óleo de soja e etanol anidro na proporção molar óleo:etanol 1:3. $\mathrm{O}$ material foi homogeneizado e a mantido sob agitação constante a $25{ }^{\circ} \mathrm{C}$. Amostras foram coletadas após $1 \mathrm{~h}, 4 \mathrm{~h}, 8 \mathrm{~h}$ e $12 \mathrm{~h}$ de incubação; centrifugadas $10.000 \mathrm{rpm}$ por $5 \mathrm{~min}$ a $4{ }^{\circ} \mathrm{C}$ e o sobrenadante descartado. O material remanescente foi então ressuspendido em tampão acetato 0.02 mol. $\mathrm{L}^{-1} \mathrm{pH} 4.2$ e a atividade lipolítica mensurada. Os experimentos foram realizados em duplicata.

Extração de lipase de mamona em diferentes tampões: Em tubos cônicos de $50 \mathrm{~mL}$ foram adicionados $2.5 \mathrm{~g}$ de extrato bruto e $25 \mathrm{~mL}$ de tampão. Uma vez homogeneizada, a suspensão foi mantida sob agitação mecânica constante a temperatura ambiente. O material foi então centrifugado a $10.000 \mathrm{rpm}$ a $4{ }^{\circ} \mathrm{C}$ por 10 minutos. $\mathrm{O}$ sobrenadante foi então recuperado e o pellet ressuspendido em $10 \mathrm{~mL}$ de acetona e filtrado a vácuo. A Tabela 1 lista os tampões utilizados e suas respectivas características.

Tabela 1 - Tampões empregados para extração de lipase de mamona. Extração realizada sob agitação a $25^{\circ} \mathrm{C}$.

\begin{tabular}{lcc}
\hline \multicolumn{1}{c}{ Tampão } & Força iônica & pH \\
\hline Citrato & $0.05 \mathrm{~mol} . \mathrm{L}^{-1}$ & 4.0 \\
Citrato & $0.05 \mathrm{~mol} . \mathrm{L}^{-1}$ & 5.0 \\
Citrato-fosfato & $0.05 \mathrm{~mol} . \mathrm{L}^{-1}$ & 4.0 \\
Citrato-fosfato & $0.05 \mathrm{~mol} . \mathrm{L}^{-1}$ & 5.0 \\
Fosfato & $0.05 \mathrm{~mol} . \mathrm{L}^{-1}$ & 6.0 \\
Fosfato & $0.05 \mathrm{~mol} . \mathrm{L}^{-1}$ & 7.0 \\
Carbonato-bicarbonato & $0.05 \mathrm{~mol} . \mathrm{L}^{-1}$ & 9.0 \\
Carbonato-bicarbonato & $0.05 \mathrm{~mol} . \mathrm{L}^{-1}$ & 10.0 \\
\hline
\end{tabular}

Determinação da atividade lipolítica: As atividades lipolíticas da suspensão e do sobrenadante após $12 \mathrm{~h}$ de incubação foram determinadas através da hidrólise de tributirina, adaptando-se o método descrito por Beisson et al., (2000). A mistura reacional contendo 14 $\mathrm{mL}$ de água destilada, $5 \mathrm{~mL}$ de tampão acetato 0.2 mol. $^{-1} \mathrm{pH} 4.2$ e $1 \mathrm{~mL}$ de tributirina foi mantida sob agitação mecânica em reator encamisado a $37^{\circ} \mathrm{C}$ por 2 minutos e então $1 \mathrm{~mL}$ de suspensão ou sobrenadante foi adicionado. A quantidade de ácido butanoico produzido foi quantificada pelo volume de KOH 0.04 mol. $\mathrm{L}^{-1}$ adicionado para a manutenção do $\mathrm{pH}$ em 4.5 . Uma unidade de atividade $\left(\mathrm{U}_{\mathrm{TBU}}\right)$ foi definida como a quantidade de enzima que libera $1 \mu \mathrm{mol}$ de ácido butanóico por minuto nas condições experimentais. As medidas de atividade lipolítica foram realizadas em triplicata.

Determinação da concentração de proteínas totais: A concentração de proteínas foi determinada de acordo com a metodologia descrita por Bradford (1976) utilizando albumina de soro bovino (BSA) como padrão 


\section{RESULTADOS E DISCUSSÃO}

A lipase de mamona desperta o interesse como biocatalisador para aplicação em processos biotecnológicos em grande parte devido ao fato de apresentar atividade máxima em valores ácidos de pH (Villeneuve 2003, Barros et al., 2010). Essa característica é especialmente interessante quando se visa aplicar a lipase de mamona como catalisador para a produção de biocombustíveis como biodiesel, especialmente no que diz respeito ao uso de óleos não refinados e residuais que apresentam elevada acidez.

A Figura 1 apresenta a estabilidade do extrato bruto de mamona em um meio reacional contendo uma mistura de óleo e etanol em uma proporção molar de $1: 3$ a $25^{\circ} \mathrm{C}$, condição essa muito semelhante à empregada em experimentos de síntese de biodiesel. Nota-se inicialmente um aumento da atividade lipolítica presente no extrato bruto, especialmente na primeira hora de reação. Este aumento pode-se ser atribuído ao mecanismo característico de lipases, que na presença de moléculas hidrofóbicas apresentam uma modificação conformacional que resulta numa maior exposição do sítio ativo da enzima (Kapoor, Gupta 2012). Todavia, com o passar do tempo, houve redução da atividade, provavelmente em virtude da presença de etanol no meio reacional, que embora seja um reagente essencial para a transesterificação pode causar inativação enzimática (Bajaj et al., 2010). Desta forma, primeiramente é necessário estabilizar a lipase de mamona de forma que esta passe a tolerar as concentrações elevadas de etanol requeridas no processo de síntese de biodiesel.

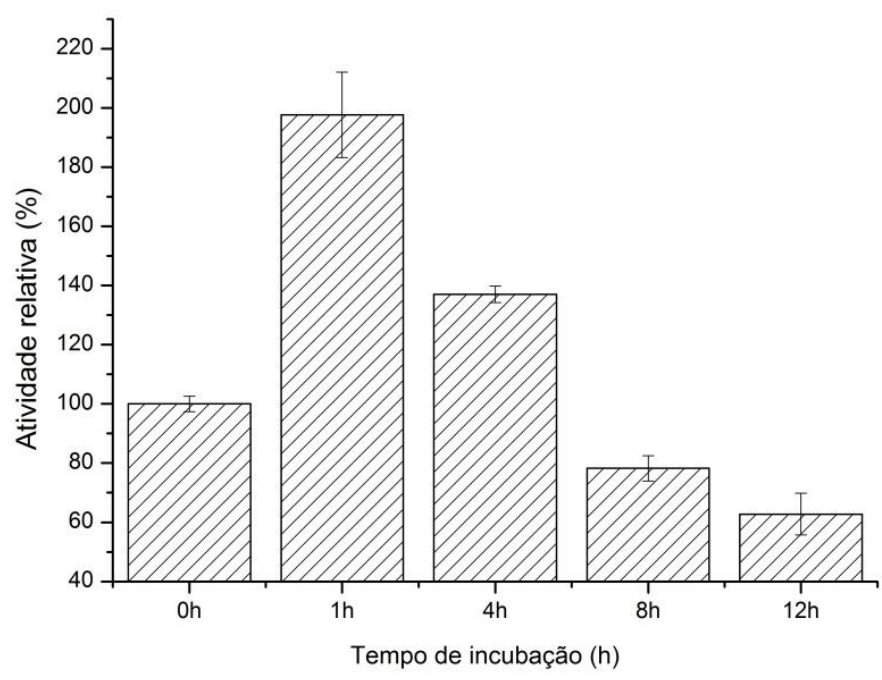

Figura 1 - Estabilidade do extrato bruto de mamona incubado em etanol-óleo de soja (relação molar de $1: 3$ ) a $25^{\circ} \mathrm{C}$. A atividade catalítica foi determinada pela hidrólise da tributirina em tampão acetato 0.2 mol.L $\mathrm{L}^{-1} \mathrm{pH} 4.5$ a $37^{\circ} \mathrm{C}$. Os valores de atividade foram normalizados considerando a atividade em tempo $0 \mathrm{~h}$ como $100 \%$. As análises foram realizadas em triplicata. 
Tendo em vista que a lipase presente no extrato bruto é gradualmente inativada na presença de etanol, surge como opção a imobilização desta enzima como estratégia para aumentar sua estabilidade operacional, de forma que possa ser empregada em condições de síntese de biodiesel. Para imobilizar esta enzima é necessário, primeiramente, solubilizar a lipase presente no extrato bruto. Com este objetivo, foram testados diferentes tampões em variados pHs a fim de avaliar a melhor condição de extração da lipase para a fase líquida. A Figura 2 apresenta a atividade relativa da lipase de mamona observada no sobrenadante após 12 horas de extração.

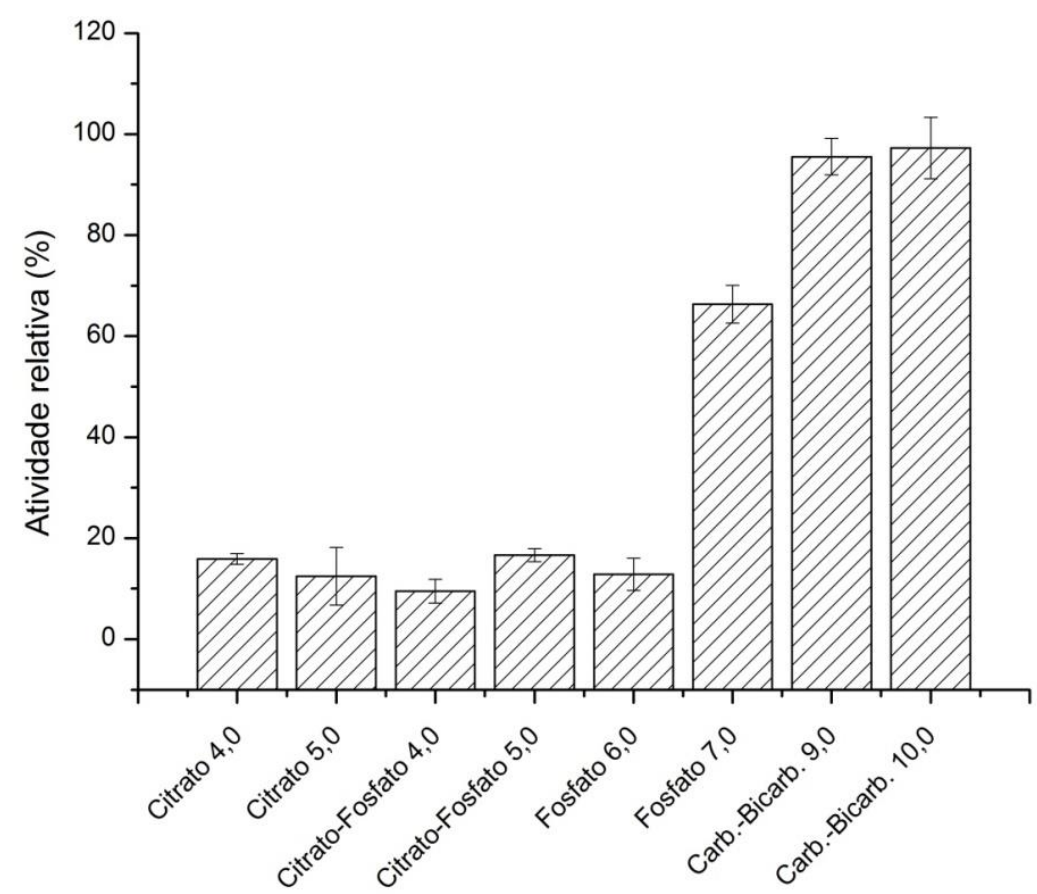

Figura 2 - Extração da lipase de mamona em diferentes tampões após 12 horas de encubação a $25^{\circ} \mathrm{C}$. Atividade relativa observada no sobrenadante em relação à atividade total observada na suspensão após 12 horas de extração. A atividade catalítica foi determinada pela hidrólise da tributirina em tampão acetato $0.2 \mathrm{~mol} . \mathrm{L}^{-1} \mathrm{pH} 4.5$ a $37^{\circ} \mathrm{C}$. Análises forma feitas em triplicata.

Embora a lipase de mamona apresente uma melhor atividade catalítica em pHs ácidos, pode-se observar que dentre os tampões avaliados houve uma melhor extração da lipase empregando tampões com valores de $\mathrm{pH}$ neutros e alcalinos. As melhores condições foram alcançadas empregando tampão carbonato-bicarbonato 0.05 mol. $\mathrm{L}^{-1} \mathrm{pH} 9.0$ e pH 10.0, onde aproximadamente $90 \%$ da atividade total observada na suspensão foi medida no sobrenadante.

A Tabela 2 apresenta a concentração de proteínas totais, a atividade observada no sobrenadante e a atividade específica $\left(\mathrm{U}_{\mathrm{TBU}} / \mathrm{mg}\right.$ de proteína) observados em cada processo de extração. Pode-se observar aumento na concentração de proteínas em solução com o aumento do $\mathrm{pH}$ do meio reacional, sendo o tampão carbonato-bicarbonato pH 10.0 o que apresentou a maior concentração de proteínas solubilizadas. 
Tabela 2 - Concentração de proteínas e atividades das soluções de extração de lipase de mamona. Concentração de proteínas determinadas pela metodologia descrita por Bradford (1976). A atividade catalítica foi determinada pela hidrólise da tributirina em tampão acetato 0.2 mol. $\mathrm{L}^{-1} \mathrm{pH} 4.5$ a $37^{\circ} \mathrm{C}$. Análises forma feitas em triplicata.

\begin{tabular}{lccc}
\hline \multicolumn{1}{c}{ Tampão } & $\begin{array}{c}\text { Proteínas totais } \\
(\mathrm{mg} / \mathrm{mL})\end{array}$ & $\begin{array}{c}\text { Atividade do } \\
\text { sobrenadante } \\
\left(\mathrm{U}_{\mathrm{TBU}} / \mathrm{mL}\right)\end{array}$ & $\begin{array}{c}\text { Atividade específica } \\
\left(\mathrm{U}_{\mathrm{TBU}} / \mathrm{mg} \text { de proteína }\right)\end{array}$ \\
\hline Citrato pH 4.0 & 1,22 & $0,80 \pm 0,03$ & 0,66 \\
Citrato pH 5.0 & 3,76 & $0,58 \pm 0,24$ & 0,15 \\
Citrato-Fosfato pH 4.0 & 1,22 & $0,45 \pm 0,13$ & 0,37 \\
Citrato-Fosfato pH 5.0 & 3,62 & $0,47 \pm 0,18$ & 0,13 \\
Fosfato pH 6.0 & 4,09 & $0,50 \pm 0,17$ & 0,12 \\
Fosfato pH 7.0 & 4,7 & $2,47 \pm 0,71$ & 0,53 \\
Carb.-Bicarbonato pH 9.0 & 5,7 & $2,81 \pm 0,57$ & 0,38 \\
Carb.-Bicarbonato pH 10.0 & 7,43 & $1,99 \pm 0,36$ & 0,27 \\
\hline
\end{tabular}

Ao se analisar os dados de atividade específica apresentados na Tabela $1 \mathrm{com}$ os dados de atividade relativa mostrados na Figura 1, observa-se que embora o tampão citrato $\mathrm{pH} 4.0$ apresente elevada atividade especifica, o tampão fosfato $\mathrm{pH} 7.0$ se mostra como melhor tampão de extração em todos os parâmetros observados uma vez que a extração nesta condição rende lipases com um menor grau de proteínas contaminantes.

\section{CONCLUSÃO}

A lipase de mamona foi extraída com sucesso para a fase aquosa empregado diversos tampões. Os melhores resultados foram observados para a extração com tampão citrato 0.05 mol. $\mathrm{L}^{-1} \mathrm{pH}$ 4.0. O resultado mais promissor foi obtido empregando tampão fosfato 0.05 mol. $\mathrm{L}^{-1} \mathrm{pH} 7.0$, onde cerca de $70 \%$ da atividade da suspensão medida no sobrenadante alcançando uma atividade específica de $0,525 \mathrm{U}_{\mathrm{TBU}} / \mathrm{mg}$ de proteína; a alta atividade específica indica a presença de uma menor concentração de proteínas contaminantes. Estes resultados demonstram a possibilidade de extração de lipase de mamona empregando uma metodologia simples e de baixo custo. Essa estratégia é economicamente atrativa visando futuros experimentos de imobilização da lipase de mamona para aplicação na síntese de biodiesel.

\section{AGRADECIMENTOS}

Os autores agradecem aos recursos disponibilizados pelo CNPQ (CNPQ/Universal 483947/2012-1) e à CAPES pela bolsa de mestrado concedida. 


\section{REFERÊNCIAS}

Adlercreutz, P. (2013). "Immobilisation and application of lipases in organic media." Chemical Society Reviews 42(15): 6406-6436.

Atabani, A. E., A. S. Silitonga, I. A. Badruddin, T. M. I. Mahlia, H. H. Masjuki and S. Mekhilef (2012). "A comprehensive review on biodiesel as an alternative energy resource and its characteristics." Renewable and Sustainable Energy Reviews 16(4): 2070-2093.

Avelar, M. H. M., D. M. J. Cassimiro, K. C. Santos, R. C. C. Domingues, H. F. de Castro and A. A. Mendes (2013). "Hydrolysis of vegetable oils catalyzed by lipase extract powder from dormant castor bean seeds." Industrial Crops and Products 44(0): 452-458.

Bajaj, A., P. Lohan, P. N. Jha and R. Mehrotra (2010). "Biodiesel production through lipase catalyzed transesterification: An overview." Journal of Molecular Catalysis B: Enzymatic 62(1): 9-14.

Barros, M., L. F. Fleuri and G. A. Macedo (2010). "Seed lipases: sources, applications and properties - a review." Brazilian Journal of Chemical Engineering 27(1): 15-29.

Beisson, F., A. Tiss, C. Rivière and R. Verger (2000). "Methods for lipase detection and assay: a critical review." European Journal of Lipid Science and Technology 102(2): 133-153.

Bradford, M. M. (1976). "A rapid and sensitive method for the quantitation of microgram quantities of protein utilizing the principle of protein-dye binding." Anal Biochem 72: 248254.

Brandon, D. L., A. M. Korn and L. L. Yang (2014). "Immunosorbent analysis of ricin contamination in milk using colorimetric, chemiluminescent and electrochemiluminescent detection." Food and Agricultural Immunology 25(2): 160-172.

Godoy, M. G., M. L. E. Gutarra, F. M. Maciel, S. P. Felix, J. V. Bevilaqua, O. L. T. Machado and D. M. G. Freire (2009). "Use of a low-cost methodology for biodetoxification of castor bean waste and lipase production." Enzyme and Microbial Technology 44(5): 317-322.

Kapoor, M. and M. N. Gupta (2012). "Lipase promiscuity and its biochemical applications." Process Biochemistry 47(4): 555-569.

Leung, D. Y. C., X. Wu and M. K. H. Leung (2010). "A review on biodiesel production using catalyzed transesterification." Applied Energy 87(4): 1083-1095.

Narwal, S. and R. Gupta (2013). "Biodiesel production by transesterification using immobilized lipase." Biotechnology Letters 35(4): 479-490.

Pierozan, M. K., R. J. da Costa, O. v. A. C. Antunes, E. G. Oestreicher, J. V. Oliveira, R. r. L. Cansian, H. Treichel and D. b. de Oliveira (2009). "Optimization of Extraction of Lipase from 
Wheat Seeds (Triticum aestivum) by Response Surface Methodology." Journal of Agricultural and Food Chemistry 57(20): 9716-9721.

Seth, S., D. Chakravorty, V. K. Dubey and S. Patra (2014). "An insight into plant lipase research - challenges encountered." Protein Expr Purif 95: 13-21.

Tüter, M. (1998). "Castor bean lipase as a biocatalyst in the esterification of fatty acids to glycerol." Journal of the American Oil Chemists' Society 75(3): 417-420.

Vescovi, V. (2012). Extração, purificação e imobilização de lipases vegetais destinadas à síntese de biodiesel e ésteres. Dissertação (Mestrado), Universidade Federal de São Carlos

Villeneuve, P. (2003). "Plant lipases and their applications in oils and fats modification." European Journal of Lipid Science and Technology 105(6): 308-317. 